\title{
The Boundaries of Librarians' and Pharmacists' Expertise: Defining What it is to be Professional (Paper)
}

\begin{abstract}
Résumé:
This paper explores findings from two separate studies to begin a conversation about how the concept of expertise, or boundaries defining professional knowledge and action, can be challenged or extended to better understand professionals' roles, identities, and contribute most effectively to society. The first study examined the identity construction of librarians and the second study examined how pharmacists' made sense of their prescribing roles. Expertise was central to both professions' understanding of themselves and their professional roles.
\end{abstract}

\section{Introduction}

The concept of expertise plays an important role in defining a profession and determining what a professional is permitted to do in society. Expertise is often conceptualized as acquired knowledge that is linked to the process of problem solving, which results in non-routine approaches to problems (Schön 1983). One of the functions of expertise is to establish and maintain boundaries. These boundaries enable professions to lay claim to specialized areas of knowledge (Abbott 1988) and determine who is, and who is not, a member of the profession. Boundaries of expertise can be challenged through engagement with technology, emerging societal issues, and dealing with complex, unusual, or unexpected problems. Librarians and pharmacists, as members of information-rich professions, practice in environments ripe with these challenges. Because of their professional roles as information and health service providers to the general public, understanding how they conceptualize their professional expertise sheds light on to how they enact their roles and relate to clients. This paper explores findings from two separate studies to begin a conversation about how the concept of expertise, or boundaries defining professional knowledge and action, can be challenged or extended to better understand professionals' roles, identities, and contribute most effectively to society. The first study examined the identity construction of librarians and the second study examined how pharmacists' made sense of their prescribing roles. Expertise was central to both professions' understanding of themselves and their professional roles.

\section{Research Design}

Both studies being reported here used a social constructionist theoretical framework and are part of larger research projects.

A discourse analysis approach from discursive psychology (Potter and Wetherell 1987) was used in both studies. Discourses are the common linguistic resources that link members of a group, like a profession. They consist of words and phrases that provide group members with a shared worldview and sense of self. The goal of a discursive psychological approach to discourse 
analysis is to explore "how utterances [both spoken and written] work" and to analyse "the rhetorical strategies in play in particular kinds of discourse" (Schwandt 2000, 197). Study one used this approach to explore the discourses librarians employ when constructing their professional identities. In study two, this approach was used to explore "possibilities that discourses make available" (Talja and McKenzie 2007, 98) for pharmacists and their professional roles.

Study one examined the identity discourse that librarians employ in three different data sources: journal articles aimed at professional librarians, email discussion lists, and research interviews. These sources were selected to provide triangulation for the results and to compare the effect of different discourses in different contexts (Talja 1999). Using reoccurring words, phrases, and ideas from the data set the data were first topically and analytically coded to facilitate analysis. The coded data were then analysed identify when and how each discourse was used and in relation to which topics.

The second study explored how pharmacists made sense of their roles as prescribers. For this study, professional role and identity were understood to be closely linked where role identity relates to how professionals understand the work they do (Pratt, Rockmann, and Kaufmann 2006). Data were collected in two phases. In the first phase, 128 professional texts describing pharmacist prescribing from four pharmacy organizations and selective journals were analyzed. Three discourses identified in the data set were analyzed for various rhetorical strategies, such as intended function, variations, tensions, and consequences. In the second phase, interviews of 20 pharmacist prescribers were analyzed using a constructivist grounded theory approach (Charmaz 2006). This approach was chosen to explore how pharmacists enacted and made sense of the prescribing role and how discourse shapes pharmacists' actions, relationships, and identities in their everyday practice.

\section{Findings}

Librarians identified themselves broadly as information experts, with specific skills in information literacy, instruction, technology, client needs, their local community, books and library-related skills, and education. Discursively, librarians used their professional expertise and skills to set boundaries for their professional practices and for their relationships with clients. Expertise was, first and foremost, used to help their clients meet their information needs. Ideally, clients would experience librarians' expertise first-hand in order to truly understand it. First-hand experience had a two-fold effect on the boundaries librarians' expertise created: First, it helped clients understand librarians' expertise; second, clients were also better able to see the boundaries of their own knowledge or expertise. Some areas of librarians' expertise, specifically technology and teaching, were positioned as placing new demands on librarians-demands librarians could not ignore. The skills and expertise associated with these areas meant librarians were needed by their clients like never before. These demands pushed at the boundaries of expertise librarians had set for themselves, gave them professional confidence, and placed them in a position to help many people. This had the unintended consequence of librarians always feeling professionally obligated to say "yes" to the new opportunities presented to them in these areas. Almost paradoxically the function of saying "yes" to new opportunities created new 
boundaries to librarians' expertise. Librarians placed limits on their professional expertise by self-policing the kind of expertise they felt their fellow librarians should possess.

Pharmacists were discursively constructed as experts in drug therapy. Prior to formal government approval of pharmacist prescribing, pharmacists' expertise functioned to justify approval of legislation and officially legitimize a role that pharmacists were previously performing in practice. There was tension in the discourse between the ideas that pharmacists had existing expertise for prescribing and pharmacists needed further expertise. Although pharmacists had existing drug therapy expertise for prescribing, further expertise in the areas of teamwork, collaboration with other health care providers, and documentation was required for them to assume the prescribing role successfully. Variations in expertise were attributed to pharmacists' education level, practice setting, and proximity to other health care professionals.. Pharmacists' expertise was positioned in relation to others and to each other, depending on practice settings and education. Those in hospital settings, working closely with physicians, or completed post-graduate training were positioned as having more expertise for the prescribing role. Pharmacists used expertise to restrict and expand the boundaries of their prescribing roles. Pharmacists prescribed within self-defined boundaries based on their own assessment of their expertise and comfort level with the disease state being treated. Similarly, they used boundaries to limit prescribing when they perceived having no expertise in a specific clinical area, relationships with patients or physicians that did not support their prescribing role, or overlapping boundaries with physicians' prescribing roles. Paradoxically, existing expertise supported expansion of their prescribing boundaries and development of additional expertise as they gained experience with their new role. An unintended consequence of the discourse of expertise manifested as pharmacists' reluctance to apply for prescribing authorization due to a lack of self-perceived expertise.

\section{Research Contribution}

Edwards's (2010) notion of relational expertise provides a useful way to understand how both librarians and pharmacists create, maintain, and transgress the boundaries of their professional expertise. She argues that in addition to using professional knowledge to solve complex problems, expertise is about "offering one's professional resources to collaborating practitioners and to clients, and working with what they offer" (p. 2). In essence, therefore, professional expertise is about building common knowledge between other professionals, clients, and communities to solve complex problems. This common knowledge creates "boundary zones" ( $p$. 46) that provide spaces where professional boundaries are negotiated. Within these boundary zones, expertise, professional values, and new opportunities for collaboration between clients and practitioners are made explicit. In study two, pharmacists' expertise was fluid, evolving, and socially constructed. When leveraging expertise to expand their prescribing role, pharmacists collaborated with patients, physicians, and other health care professionals, to modify or establish new boundaries, relationships, and processes. Edwards's work highlights the need for professionals to remain open-minded when working within boundary zones. But, as the selfpolicing of librarians' expertise that occurred in study one indicated, such open-mindedness can be difficult as it challenges entrenched professional practices. 
Understanding expertise as the boundaries that define professional knowledge and action provides an excellent way to understand the information-intensive work of professionals like librarians and pharmacists. Edwards (2010) connects expertise to professional identity, arguing that when the boundaries of expertise are negotiated people's professional identities are similarly negotiated and mediated. Edwards's definition of professional identity is simple: identity is "an organising principle for action: we approach and tackle what we think we are able to change and make changes in line with what matters to us: our interests" (p. 10). By paying attention to the shifting boundaries of expertise, we can identify not only what matters to professionals in information-intensive fields, but also the language used to describe their work, what professionals do, and how to begin conversations to improve collaborations with clients, stakeholders, and other professionals.

\section{Reference List:}

Abbott, A. (1988). The system of profession: An essay on the division of expert labor. Chicago, IL: University of Chicago Press.

Charmaz, K. (2006). Constructing grounded theory: A practical guide through qualitative analysis. London: Sage Publications.

Edwards, A. (2010). Being an expert professional practitioner: The relational turn in expertise. New York, NY: Springer.

Potter, J., \& Wetherell, M. (1987). Discourse and social psychology. London: Sage Publications.

Pratt, M. G., Rockmann, K. W., \& Kaufmann, J. B. (2006). Constructing professional identity: The role of work and identity learning cycles in the customization of identity among medical residents. Academy of Management Journal, 49(2), 235-262.

Schön, D. A. (1983). The reflective practitioner: How professionals think in action. New York, NY: Basic Books.

Schwandt, T. A. (2000). Three epistemological stances for qualitative inquiry: Interpretivism, hermeneutics, and social constructionism. In N. K. Denzin \& Y. S. Lincoln (Eds.), Handbook of qualitative research (2nd ed., pp. 189-213). Thousand Oaks, CA: SAGE Publications.

Talja, S., \& McKenzie, P. J. (2007). Editors' introduction: Special issue on discursive approaches to information seeking in context. Library Quarterly, 77(2), 97-108 